\title{
AN ADVECTIVE HYPOTHESIS FOR THE FORMATION OF THE STRATOSPHERIC AEROSOL LAYER
}

\author{
M. KRITZ \\ Centre des Faibles Radioactivités, Laboratoire mixte CNRS-CEA \\ 91190 Gif-sur-Yvette, France
}

\begin{abstract}
Résumé. - Dans un travail précédent, nous sommes arrivés à la conclusion que les grandes particules ( $\sim .3 \mu \mathrm{m}$ de rayon) de la couche stratosphérique d'aérosols sont formés par un processus de nucléation hétérogène et qu'un facteur important de la distribution en taille des aérosols est le nombre de particules susceptibles de servir de noyau dans ce processus hétérogène.

Dans cet article, nous envisageons 2 sources possibles pour ces noyaux : leur transport depuis la troposphère et leur formation homogène dans la stratosphère.

En utilisant un modèle numérique simple, on montre que si une nucléation homogène avait lieu dans la stratosphère, il en résulterait en général un nombre relativement grand $\left(10 \mathrm{~cm}^{-3}\right)$ de nouvelles particules, ce qui, compte tenu de nos travaux précédents, apparait incompatible avec la formation des grandes particules telles qu'elles sont observées.

On remarque également qu'un transport vertical par diffusion, depuis la troposphère conduirait aussi à un nombre trop grand de particules.

Au contraire, si l'air était entraîné dans la stratosphère par un mouvement ascensionnel au cours des orages tropicaux intenses, cette advection verticale conduirait à la faible concentration de particules attendue, et serait également compatible avec les autres propriétés de la couche stratosphérique d'aérosols.
\end{abstract}

\begin{abstract}
In earlier work we concluded that the large $(\sim 0.3 \mu \mathrm{rad})$ particles of the stratospheric aerosol layer are formed by a heterogeneous nucleation process, and that a primary factor controlling the particle size distribution of the aerosol is the number of particles available to serve as nucleation sites for the subsequent heterogeneous formation process. In this paper two possible sources of these sites are considered; transport from the troposphere, and homogeneous formation in the stratosphere. Using a simple numerical model, it is shown that if homogeneous nucleation occurred in the stratosphere it would, in general, result in the formation of relatively large $\left(\sim 10 \mathrm{~cm}^{-3}\right)$ numbers of new particles, which our previous work has shown to be incompatible with the formation of the observed large particles. It is also pointed out that vertical diffusive transport from the troposphere would also introduce unacceptably large numbers of particles, but that vertical advection, in which air enters the stratosphere in the updrafts of intense tropical thunderstorms, would have the requisite low particle concentrations and also be compatible with other observed properties of the stratospheric aerosol layer.
\end{abstract}

In previous work $[1,2]$ we presented the results of a quantitative analysis of the evolution of the particle size distribution of the stratospheric aerosol, demonstrating that the large $(\sim 0.3 \mu \mathrm{rad})$ particles of the layer are formed by a heterogeneous nucleation process, and that a primary factor controlling the particle size distribution of the aerosol is the number of particles initially available to serve as nucleation sites for the subsequent heterogeneous formation process. Three possible sources of such sites were identified : 1) diffusion from the upper troposphere; 2) advection from the troposphere; and 3) formation in the stratosphere. In this talk ( $\left.{ }^{1}\right)$ I wish to describe

( ${ }^{1}$ ) This paper is a summary of a communication presented at the Congrès de la Société Française de Physique, Dijon, 30 juin4 juillet 1975 . our recent work, in which we have attempted to differentiate between these three potential sources, and to call attention to what we feel are the principal problems and next steps to take in understanding the origin and attributes of the stratospheric aerosol.

As in our earlier works, we are primarily concerned here with the stratospheric aerosol as it existed in the early 1960 's, a period of relatively low volcanic activity which was terminated by the eruption of Mt Agung in March, 1963. While it is unquestioned that volcanic eruptions are responsible for the injection of large quantities of gases and particles into the stratosphere, prior to the period 1960-1963, during which the observations relevant to this work were made, the last reported penetration of the tropopause by a volcanic plume occurred during the eruption 
of Bezmhnnaja in $1956[3,4]$. Because the interval between this eruption and these observations was 2-3 times greater than the 1-1/2-2 year mean residence time for the lower stratosphere, and because the concentrations of aerosol observed in the interval 1960-1963 did not show any systematic variation (as opposed to the sharp increase and monotonic decrease observed after Mt. Agung and subsequent observations) we have postulated that the 19601963 observations are representative of a background concentration of aerosol, maintained by normal atmospheric processes, and frequently overwhelmed by the much larger concentrations of aerosol resulting from major volcanic eruptions.

The principal characteristics of the stratospheric aerosol layer as it existed in the early 1960's were delineated by the work of Junge, Chagnon and Manson [5]; Mossop [6], and Friend [7]. The undisturbed layer is characterized by a bimodal particle size distribution consisting of a $\sim 1 \mathrm{~cm}^{-3}$ population of Aitken nuclei and $\mathrm{a} \sim 0.05-0.1 \mathrm{~cm}^{-3}$ population of large particles with a mean radius of $0.3 \mu$. The nominal mass concentration of the aerosol comprising the layer was $1 \times 10^{-14} \mathrm{~g} \mathrm{~cm}^{-3}$ at $20 \mathrm{~km}$. Composition of the particles was dominated by sulfate, generally thought to be present as $75 \%$ sulfuric acid. Figures 1 and 2 summarize this information for the large particles comprising the layer. (The vertical distribution of Aitken nuclei in the lower stratosphere was not peaked, but had a more or less uniform mixing ratio between 15 and $25 \mathrm{~km}$ [8].)

In our earlier work, we concluded that an initial stratospheric concentration of about 0.1 heterogeneous nucleation sites per $\mathrm{cm}^{-3}$ was a necessary condition for the formation of the $0.3 \mu$ particles characterizing the stratospheric aerosol layer, and particularly noted that significantly larger initial concentrations would lead to the formation of an aerosol with a characteristic size of $0.1 \mu$ or less. In that work we discussed three possible sources for these nucleation sites in the stratosphere, pointing

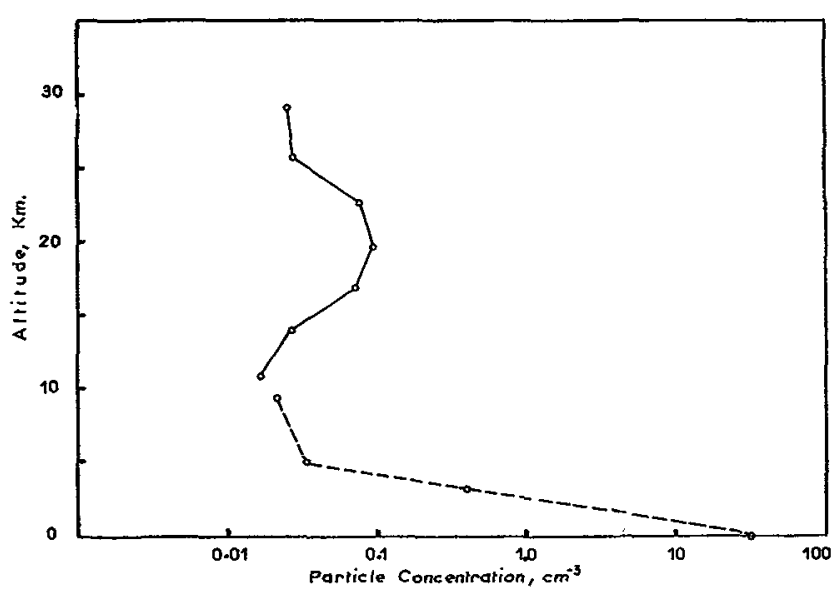

FIG. 1. - Large $(r \geqslant 0.1$ micron) particle concentration versus altitude in the troposphere and lower stratosphere (Junge, 1963).

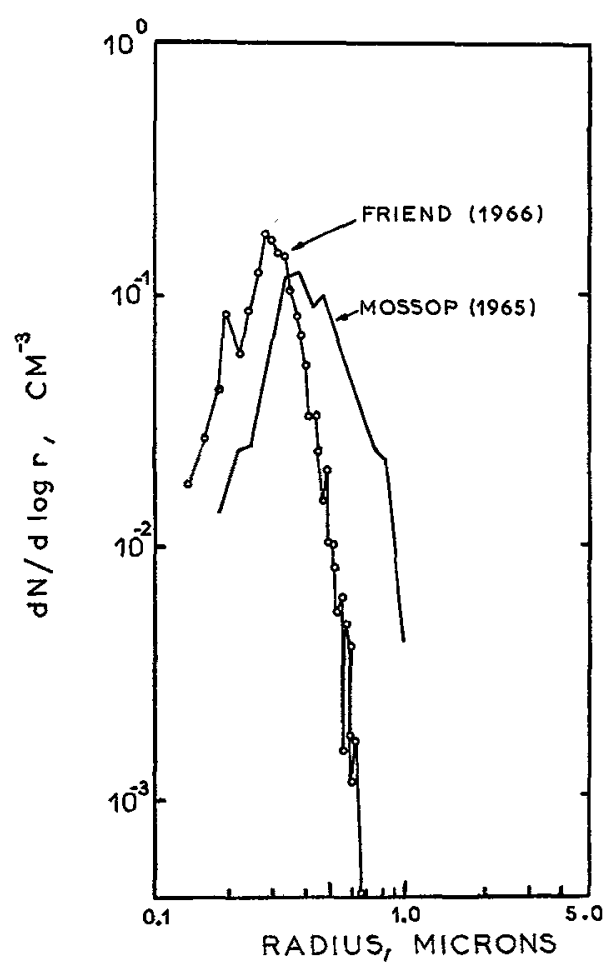

Frg. 2. - Observed large particle size distribution of the stratospheric aerosol.

out that the first of these, diffusive transport from the upper troposphere, was incompatible with both the observed Aitken nuclei concentrations in the stratosphere (which were about two orders of magnitude smaller than the values which would result from diffusive transport) and the requisite initial concentration of nucleation sites (assuming that all such particles were equally capable of serving as heterogeneous nucleation sites for the stratospheric aerosol). On the other hand, it is expected that advective transport would introduce much lower, $<1 \mathrm{~cm}^{-3}$, concentrations of Aitken nuclei, a figure which is compatible with both the observed stratospheric concentrations and the requisite initial concentration of heterogeneous nucleation sites. It was also suggested that the formation of small concentrations of nuclei via a homogeneous mechanism, while unlikely, might conceivably occur under certain special conditions. These two possibilities, advective transport and homogeneous nucleation; are discussed below.

1. The Vertical Advection Hypothesis. - The shape of the vertical profiles of the large stratospheric particles (cf. Fig. 1) and the more or less uniform global distribution of the layer suggested that the aerosol was formed in the stratosphere by reaction between reactive species found in that region (such as $\mathrm{O}$ or $\mathrm{O}_{3}$ ) and sulfur-bearing gases (generally taken to be $\mathrm{SO}_{2}$ ) diffusing across the tropopause from the upper troposphere. This manner of origin, which I shall refer to as the Vertical Diffusion Hypothesis, was first proposed and recently reviewed by Junge et al. $[5,9,10]$. 
An alternate explanation for the observed spatial distribution of the stratospheric aerosol layer is that the (sulfur-bearing) gases enter the stratosphere in the ascending leg of the tropical Hadley circulation. There is a growing body of evidence that most air (and water vapor) entering the stratosphere does so in this manner $[11,12,13]$; however it is important to note that the actual vertical motion does not take place via the slow $\left(\sim 0.1 \mathrm{~cm} \mathrm{~s}^{-1}\right)$ average upwelling velocity of the circulation, but instead in the updrafts of intense convective cells (i.e., thunderstorms) where velocities are on the order of tens of meters per second $[14,15]$. These storms are of varying intensity and only a small fraction penetrates the high (16$18 \mathrm{~km}$ ) tropical tropopause. Air (and trace constituents) injected in this manner are mixed poleward along isentropic surfaces, and eventually mix back into the troposphere in mid-latitudes, following the pathway for ozone outlined by Dutsch [16]. Thus under this hypothesis (which I shall refer to as the Vertical Advection Hypothesis) the height of the layer and its similarity between hemispheres are primarily controlled by transport rather than chemical considerations.

Newell $[13,15]$ has estimated the annual flux of air entering the stratosphere through the tropical tropopause to be about $1 \times 10^{20} \mathrm{~g} \mathrm{yr}^{-1}$, and pointed out [15] that most of this transfer occurs in three areas of "enhanced vertical motion" located over South America, Africa, and the "oceanic continent " of the western Pacific. A schematic drawing of the general structure of the convective storms responsible for this transfer is shown in figure 3 [17]. This figure illustrates two important aspects of these storms : first, that the rapidly rising air in the core of the storm originates within one or two kilometers of the surface; and second, that the air contained in the core does not mix appreciably with air at intermediate levels during its ascent [18]. Therefore under the Vertical Advection Hypothesis the relevant $\mathrm{SO}_{2}$ (or perhaps DMS, $\mathrm{H}_{2} \mathrm{~S}$

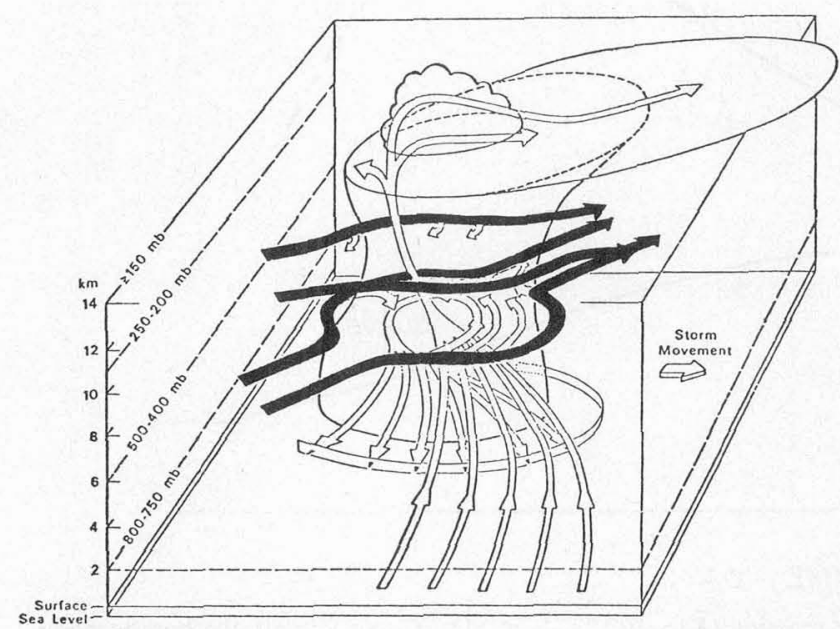

Frg. 3. - Schematic drawing of a thunderstorm cell showing advective transport in the core from the surface to high altitude (NCAR, 1971). or OCS) concentrations to consider are those of the lower troposphere, particularly in the areas of enhanced vertical motion identified by Newell.

Lodge et al. [19] measured $\mathrm{SO}_{2}$ concentrations in the tropics, and suggested $0.9 \mathrm{ppb}\left(\sim 2.5 \mu \mathrm{g} \mathrm{m}^{-3}\right)$ as an average value over tropical land masses. Combining this value with Newell's estimated flux and our earlier estimate [1] that between $2 / 3$ and $4 / 5$ of the $\mathrm{SO}_{2}$ originally present in air entering the updraft would be removed by precipitation during its ascent, gives an annual stratospheric sulfate input (assuming the lower transport efficiency and a relatively fast sulfateforming reaction) of about $6 \times 10^{10} \mathrm{~g} \mathrm{yr}^{-1}$. This result agrees well with the budget based on the observed properties of the stratospheric aerosol layer. Taking the mean sulfate concentration as $0.75 \times 10^{-14} \mathrm{~g} \mathrm{~cm}^{-3}$, a $5 \mathrm{~km}$ layer thickness and $80 \%$ coverage of the earth gives a total sulfate mass of about $1.5 \times 10^{10} \mathrm{~g}$, a quantity which is also approximately equal to the annual budget estimated taking 1 year as the mean residence time for large particles in the lower stratosphere. It is also interesting to note that the stratospheric sulfate concentrations resulting from the proposed advective transport are about $7.5 \times 10^{-14} \mathrm{~g} \mathrm{~cm}^{-3}$, again in good agreement with the observations if we allow for the fact that the stratospheric aerosol layer is composed of numerous laminar sublayers [39] with sulfate concentrations 2-3 times the average for the layer as a whole.

During the advective transport to the stratosphere particles are removed from the rising column of air by precipitation. Particles larger than about $0.1 \mu$ are removed by serving as condensation nuclei, and by collisions with falling raindrops, while smaller particles are removed by diffusion to and incorporation in cloud droplets $[20,21,22]$. While it is difficult to make a quantitative estimate for the exact concentration of aerosol particles which would escape scavenging (we call this population the «residual aerosol ») it is clear that the concentration would be quite small, certainly on the order of $1 \mathrm{~cm}^{-3}$ or less, and most probably with radii in the interval $0.01-0.1 \mu$.

Thus the Vertical Advection Hypothesis appears to be compatible with the observed properties of the stratospheric aerosol (mass concentration, height at $20 \mathrm{~km}$, similarity between hemispheres), the estimated mass budget, and the low initial aerosol populations required by the observed low Aitken nuclei concentrations and for the formation of the observed large particles.

2. Homogeneous formation of nuclei in the stratosphere. - The creation of aerosol via the homogeneous nucleation of new particles is a more or less continuous process in the continental troposphere $[23,24]$, and could conceivably occur in the stratosphere as well. Using the numerical model refered to earlier, we have shown that this cannot be the primary mechanism of formation for the strato- 
spheric aerosol, but now wish to consider the possibility that this mechanism is responsible for the formation of a very limited number $\left(\sim 1 \mathrm{~cm}^{-3}\right)$ of particles which could then serve as heterogeneous nucleation sites for the subsequent formation of the large particles of the stratospheric aerosol.

We begin by considering a parcel of stratospheric air containing $\mathrm{ppb}$ concentrations of a gaseous sulfur compound, taken for purposes of discussion to be $\mathrm{SO}_{2}$, and $\mathrm{ppm}$ concentrations of water vapor, and assume that $\mathrm{SO}_{3}(\mathrm{~g})$ is being formed by a first-order reaction. In the absence of losses the $\mathrm{SO}_{3}$ concentration is obtained by solving the equation :

$$
\begin{gathered}
\frac{\mathrm{d}\left[\mathrm{SO}_{3}\right]}{\mathrm{d} t}=k\left[\mathrm{SO}_{2}\right] \\
{\left[\mathrm{SO}_{3}\right]=\left[\mathrm{SO}_{2}\right]_{0}\left(1-\mathrm{e}^{-k t}\right) .}
\end{gathered}
$$

In general, the rate of homogeneous particle formation, or nucleation, is a function of the concentration of the condensing species and the thermodynamic properties of the various phases; thus for a concentration $x$ of $\mathrm{SO}_{3}$ and $y$ of $\mathrm{H}_{2} \mathrm{O}$, stable sulfuric acid-water-nuclei will be formed at a rate $z$ which can, in principle, be predicted if the necessary thermodynamic information is available $[25,26]$.

Once formed, these particles immediately become heterogeneous nucleation sites for the $\mathrm{SO}_{3}$ and $\mathrm{H}_{2} \mathrm{O}$ present, so that a sink term must be added to eq. (1a) :

$$
\frac{\mathrm{d}\left[\mathrm{SO}_{3}\right]}{\mathrm{d} t}=k\left[\mathrm{SO}_{2}\right]-\sum_{i} K\left(\mathrm{SO}_{3}, r_{i}\right) n_{i}\left[\mathrm{SO}_{3}\right]
$$

Here $K$ is the collision coefficient between $\mathrm{SO}_{3}$ molecules and particles of radius $r_{i}$, and $n_{i}$ is the concentration of such particles. Assuming that sufficient $\mathrm{SO}_{2}$ is originally present, the concentration of $\mathrm{SO}_{3}$ in such a system will first build up to a level where aerosol formation occurs, continue to increase, though at a diminishing rate (as the particles grow they become more effective $\mathrm{SO}_{3}$ sinks) until a point is reached where the $\mathrm{SO}_{3}$ production rate is balanced by the rate at which $\mathrm{SO}_{3}$ is being taken up by the aerosol present, and a maximum in $\mathrm{SO}_{3}$ concentration occurs. This behavior is illustrated by curve 1 in figure 4, obtained using a simple numerical model based on equation 2 and assuming an initial $\mathrm{SO}_{2}$ concentration of $0.024 \mathrm{ppb}\left(4.6 \times 10^{7}\right.$ molecules $\mathrm{cm}^{-3}$, sufficient to form $1 \times 10^{-14} \mathrm{~g} \mathrm{~cm}^{-3}$ of $75 \%$ sulfuric acid-water aerosol), a first order reaction rate coefficient of $10^{-7} \mathrm{~s}^{-1}$, and the additional assumption that the formation of 1 particle per $10 \mathrm{~cm}^{-3}$ occurs when the $\mathrm{SO}_{3}$ concentration reaches $1 \times 10^{7} \mathrm{~cm}^{-3}$. $\left(\mathrm{A} \mathrm{SO}_{3}\right.$ concentration threshold for nucleation is assumed because accurate thermodynamic data is not available for sulfuric acid water aerosols under stratospheric conditions; thus the homogeneous nucleation theory cannot be directly applied.)

The importance of this computation is that for these particular conditions, which are well within the range of possible initial concentrations and reaction rate coefficients for the stratosphere, it shows that after the initial assumed nucleation of 0.1 particle $\mathrm{cm}^{-3}$ occurs the $\mathrm{SO}_{3}$ concentration continues to increase, reaching a peak value of about $1.2 \times 10^{7} \mathrm{~cm}^{-3}$ nine days later, and finally dropping

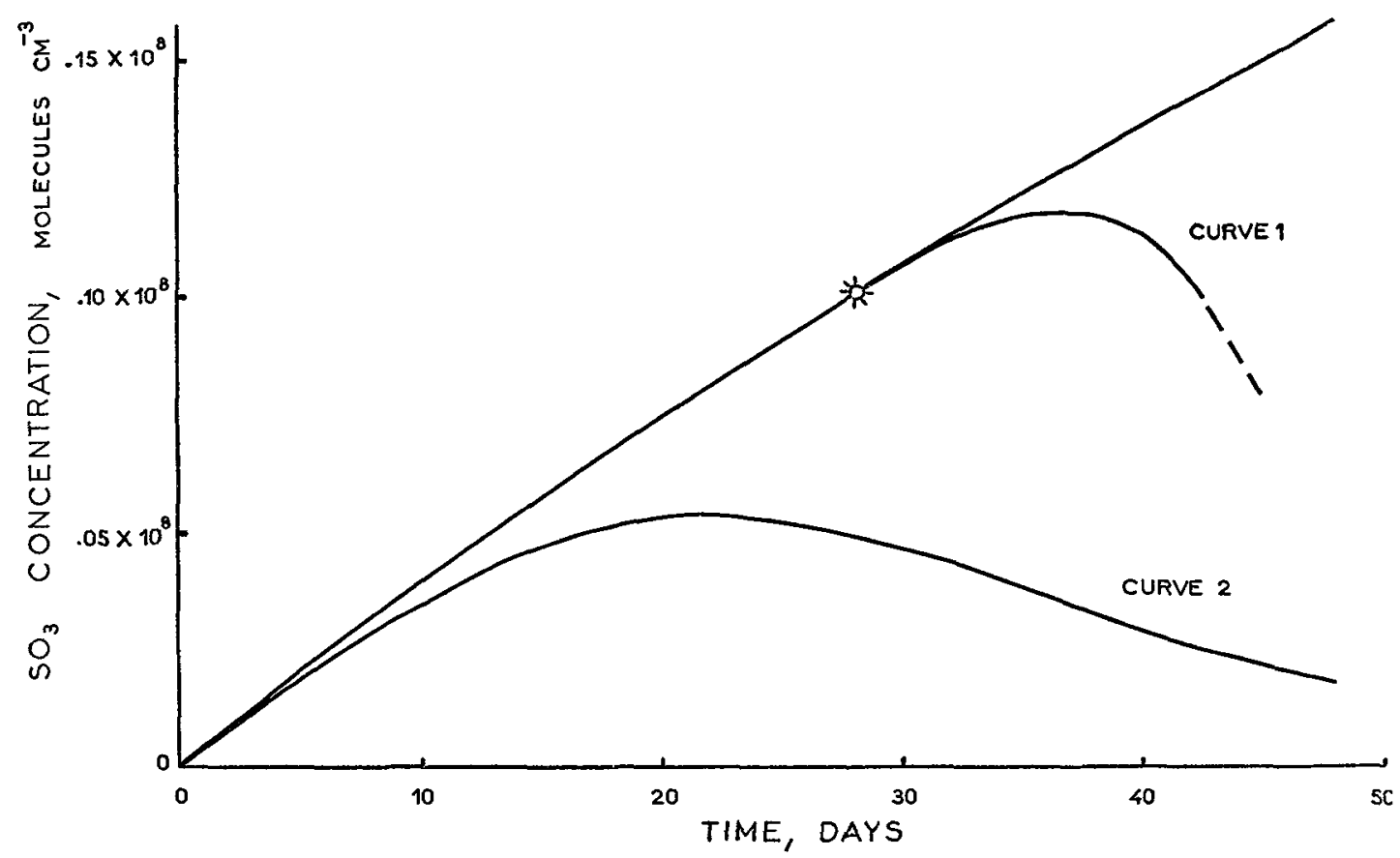

Fig. 4. $-\mathrm{SO}_{3}$ concentration versus time resulting from the first-order reaction $\left(K=10^{-7} \mathrm{~s}^{-1}\right)$ of $\mathrm{SO}_{2}$. Curve $1:$ with the homogeneous nucleation of 0.1 particles occurring at $\left(\mathrm{SO}_{3}\right)=1 \times 10^{7} \mathrm{~cm}^{-3}$. Curve 2 : with heterogeneous nucleation on a $0.1 \mathrm{~cm}-{ }^{3}$ aerosol population present at $t=0$. The $\mathrm{SO}_{2}$ concentration initially present $\left(4.63 \times 10^{7}\right.$ molecules $\left.\mathrm{cm}^{-3}\right)$ is sufficient to produce $1 \times 10^{-14}$ gm $^{-3}$ of $75 \%$ sulfuric acid-water aerosol. 
back below the $1 \times 10^{7} \mathrm{~cm}^{-3}$ threshold level about fourteen days after the initial nucleation. The question is, given this initial nucleation, how many additional new particles would be nucleated in the fourteen day interval during which the $\mathrm{SO}_{3}$ concentrations are higher than those obtaining when the initial nucleation occurred?

For the sulfuric acid-water system at room temperature, the homogeneous nucleation theory indicates that for the low concentrations of condensing species and slow nucleation rates in question, the rate of nucleation is extremely sensitive to small changes in $\mathrm{SO}_{3}$ concentration. For example, the computations of Mirabel and Katz [25] show that this rate could vary with the tenth or twelth power of $\mathrm{SO}_{3}$ concentration. If this is also the case for stratospheric conditions, then the rate of nucleation at the peak $\mathrm{SO}_{3}$ concentration of $1.2 \times 10^{7} \mathrm{~cm}^{-3}$ could be about ten times $\left(1.2^{12}\right)$ the rate obtaining at $1 \times 10^{7} \mathrm{~cm}^{-3}$. In other words, for the conditions of the computation shown in figure 4 the results suggest that if the initial nucleation of 0.1 particle $\mathrm{cm}^{-3}$ occurred at a $\mathrm{SO}_{3}$ concentration of $1 \times 10^{7} \mathrm{~cm}^{-3}$, then the additional nucleation that would occur while the $\mathrm{SO}_{3}$ concentration exceeded this threshold value would probably lead to the nucleation of ten or twenty times this number of additional particles, a situation which our previous computations have shown to be incompatible with the formation of the large particles of the stratospheric aerosol.

We have performed similar computations for various initial $\mathrm{SO}_{2}$ concentrations, reaction rates and threshold values for initial nucleation, and found that the nucleation of additional particles after the initial nucleation is favored by higher initial $\mathrm{SO}_{2}$ concentrations, faster reaction rates, and lower threshold values for the initial nucleation, with the opposite conditions having the opposite effect. For example, figure 5 shows the result of a computation similar to the one just described except that a reaction rate coefficient of $10^{-8} \mathrm{~s}^{-1}$ was assumed. We see that the peak $\mathrm{SO}_{3}$ concentration is only about 1 percent higher than the assumed threshold value, suggesting that in this case the nucleation of additional particles would be less likely than in the preceeding computation. However, for these slower reaction rates, two other factors become important. First, even small concentrations of residual particles will restrict the maximum $\mathrm{SO}_{3}$ concentrations to low values; this is shown by curve 2 in the figures, which was computed for an initial concentration of $0.1 \mathrm{~cm}^{-3} 0.046 \mu$ particles. Second, about 280 days must elapse before the threshold value for nucleation is reached with about an additional year required for the particle to grow to $0.2 \mu \mathrm{rad}$. (The rate of growth is restricted by the slow reaction rate and resultant low $\mathrm{SO}_{3}$ concentrations.) This timescale appears to be incompatible with the 1 year residence times estimated for particles in the lower stratosphere. However, if we try to speed things up by postulating a higher initial $\mathrm{SO}_{2}$ concentration or a lower nucleation threshold we find that the peak $\mathrm{SO}_{3}$ concentrations again become appreciably higher than the threshold levels, favoring the nucleation of additional particles.

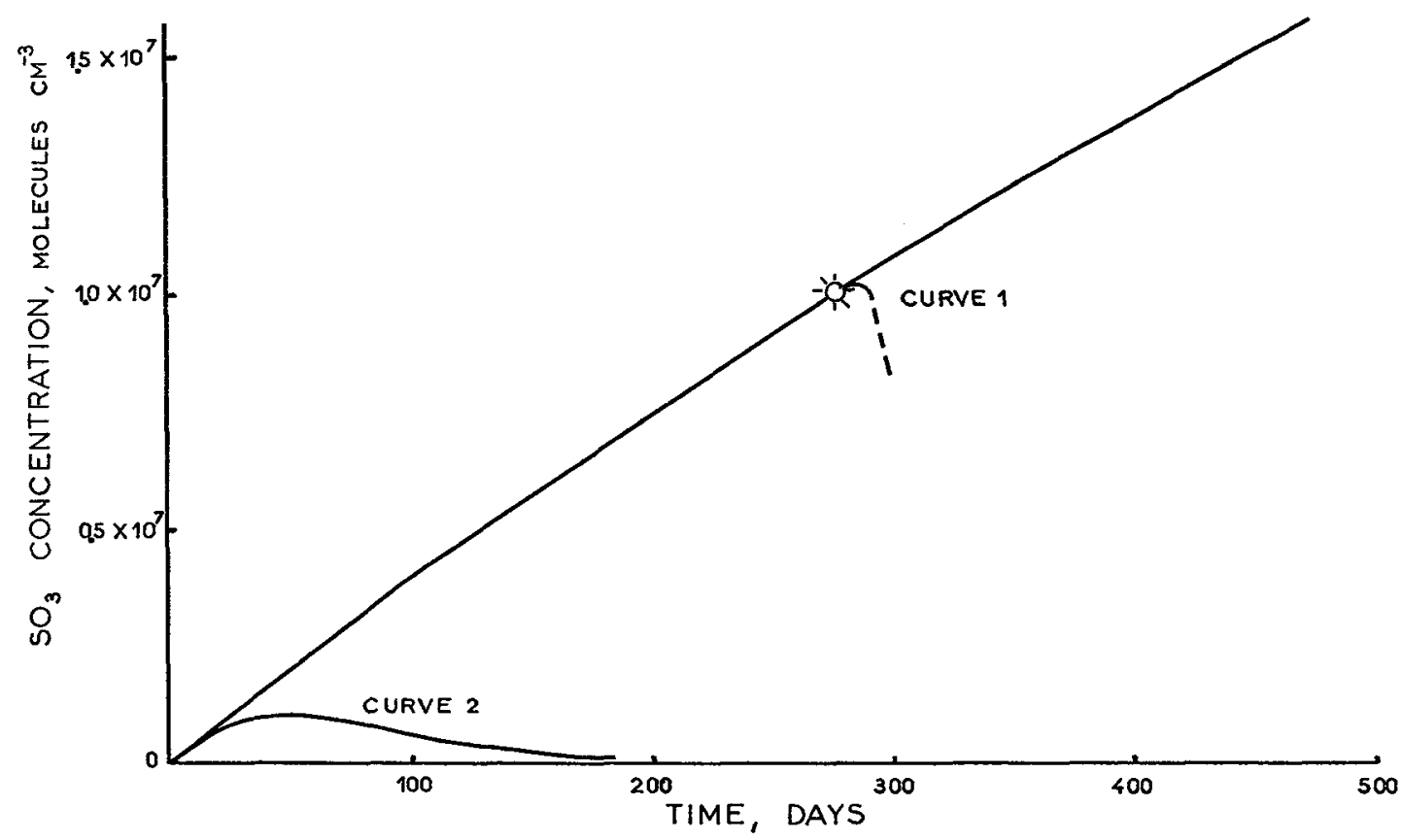

FIG. 5. $-\mathrm{SO}_{3}$ concentration versus time resulting from the first-order reaction $\left(K=10^{-.8} \mathrm{~s}^{-1}\right)$ of $\mathrm{SO}_{2}$. Curve 1 : with the homogeneous nucleation of 0.1 particles occurring at $\left(\mathrm{SO}_{3}\right)=1 \times 10^{7} \mathrm{~cm}^{-3}$. Curve $2:$ with heterogeneous nucleation on a $0.1 \mathrm{~cm}^{-3}$ aerosol population present at $t=0$. The $\mathrm{SO}_{2}$ concentration initially present $\left(4.63 \times 10^{7}\right.$ molecules $\left.\mathrm{cm}^{-3}\right)$ is sufficient to produce $1 \times 10^{-14} \mathrm{gm}^{-3}$ of $75 \%$ sulfuric acid-water aerosol. 
Although additional computations with other combinations of variable (and a more sophisticated model) might be made, the present results are sufficient to illustrate the relevant factors and to demonstrate that while the possible importance of this process cannot be completely ruled out, it could occur only under a very restricted range of conditions. Additional information on the actual reaction rate, and the dependence of the nucleation rate on $\mathrm{SO}_{3}$ concentration would allow a more conclusive evaluation to be made.

3. Additional considerations. - In addition to the preceeding discussion, several other important points shoulld be briefly mentioned. First, in the discussion thus far we have tacitly assumed that any stable particles present in the stratosphere will act as a heterogeneous nucleation site for the stratospheric aerosol. This is not the case for the nucleation of water in the troposphere, where only a fraction of the total aerosol population serve as cloud condensation nuclei (CCN). Junge and McLaren [27] and Fitzgerald [28] have shown that this behavior is due to differences in size and (water) solubility between particles; while most particles could presumably nucleate water if the supersaturation were sufficiently high, in the atmosphere supersaturations rarely exceed a few tenths of a percent because of the rapid removal of water vapor by droplets which formed on particles activated at lower supersaturations. Because of the extremely low vapor pressure and chemical properties of sulfuric acid vapor one would not expect a similar effect in the formation of the stratospheric aerosol. However, because the tropospheric particles entering the stratosphere, whether by advection or diffusion, would tend to be those which because of some physical or chemical property - for example, insolubility had survived the precipitation removal process, it is not entirely inconceivable that such an effect might occur. The next step is to study the problem experimentally, and we have initiated a program to do so.

Another aspect of the problem which has not been discussed per se is the bimodal character of the particle size distribution. The two most likely ways that such a distribution could evolve in the stratosphere are either as a result of the effect discussed above, in which only a small fraction of the Aitken population serve as heterogeneous nucleation sites and grow into the large size range, leaving the remainder of the population unchanged in size, or by the presence of the large and Aitken populations in separate parcels of stratospheric air.

Another brief comment can be addressed to reports [29] that lidar soundings of the stratosphere showed that no large particles were present for extended periods in 1971. We point out that the absence of large particles does not necessarily imply the absence of the layer, but rather that the particles present were smaller than the minimum size $(\sim 0.1 \mu)$ detectable by the lidar measurements. As shown in our earlier work, this situation could arise if a large number of heterogeneous nucleation sites were available in the stratosphere. This might have occurred as a result of volcanic activity, as three important eruptions occurred in 1970 [4].

Finally, I wish to comment briefly on the present controversy regarding the possible depletion of stratospheric ozone by man-made fluorocarbons $[30,31$, 32]. The stratospheric ozone layer is of course present in a more or less steady-state concentration determined by the balance between its various sources and sinks [33, 34, 35] and it has been suggested that compounds such as Freon-11 $\left(\mathrm{CFCl}_{3}\right)$ or Freon-12 $\left(\mathrm{CF}_{2} \mathrm{Cl}_{2}\right)$, which do not have any known tropospheric sinks, will eventually reach the stratosphere where they will be dissociated by ultraviolet radiation. It is argued that the $\mathrm{Cl}$ atoms thus released will then participate in the catalytic destruction of ozone, creating a significant new stratospheric sink and materially reducing the steady state ozone concentration in the stratosphere.

What I wish to point out here is that these computations have apparently neglected the possibility that appreciable concentrations of natural chlorine compounds may already be present in the stratosphere. Measured concentrations of such gases (thought to be present at $\mathrm{HCl}$ ) are about $1 \mathrm{ppb}$ in the tropasphere $[36,37]$; and the presence of other species has also been reported [38]. If we consider transport by vertical advection and assume $90 \%$ scavenging by precipitation, a $1 \mathrm{ppb}$ tropospheric concentration gives a figure of about $1.3 \times 10^{35} \mathrm{Cl}$ atoms per year entering the stratosphere, compared with about $0.8 \times 10^{34} \mathrm{Cl}$ atoms per year derived from present rates of fluorocarbon manufacture. This result does not, of course, solve the problem, if only because the transport efficiency used above is only a crude guess; what it does do is suggest that the presence of relatively large concentrations of naturally derived $\mathrm{Cl}$ in the stratosphere is not at all out of the question, and should be investigated before coming to any final conclusions on the fluorocarbon-ozone question.

4. Summary. - While different workers have, of course, differing degrees of interest in the various aspects of what may be called the stratospheric aerosol problem, in our analytical work we have been principally concerned with questions relating to the particle size distribution of the stratospheric aerosol and the nature of aerosol-forming mechanism. This in turn has led to other questions, such as the source of the gases that react to form the stratospheric aerosol, the rate of this reaction, and the means of transport of these gases (and any accompanying aerosol) to and within the stratosphere.

In particular, two means of transport to the stratosphere have been considered : vertical diffusion, occurring more or less uniformly over the earth's 
surface, and vertical advection, in which stratospheric injection occurs near the Equator. At the present time, it is difficult to make a definitive choice between these two mechanisms. In his analysis of the Vertical Diffusion Hypothesis Junge [10] used a one-dimensional diffusion-reaction-sedimentation model which considered the vertical distribution of sulfate. This model did not give any information on the mechanism of aerosol formation (homogeneous or heterogeneous), but did establish the condition that under the Vertical Diffusion Hypothesis the observed location of the stratospheric aerosol layer at $20 \mathrm{~km}$ was incompatible with reaction rate coefficients faster than about $10^{-8} \mathrm{~s}^{-1}$. On the other hand our analysis $[1,2]$ which considered the particle size distribution of the aerosol rather than its vertical distribution in space, established the requirement for a heterogeneous formation mechanism, and pointed up the requirement that only a limited number of heterogeneous nucleation sites be available, but did not give any direct information on the required rate of reaction. (It was found that the important features of the final aerosol particle size distribution were relatively insensitive to reaction rate). Therefore the two analyses are not in conflict, since they speak to different aspects of the problem. Together, they set some important constraints on the possible modes of origin of the stratospheric aerosol, and point to three specific areas of research where additional information would be very useful. These are 1) determination of the rates of reaction for species such as $\mathrm{SO}_{2}, \mathrm{H}_{2} \mathrm{~S}$, DMS, etc., under stratospheric conditions; 2) experimental studies of heterogeneous nucleation processes under stratospheric conditions, and 3) further studies of the troposphereto-stratosphere exchange.

Acknowledgments. - Since my arrival in France, I have had the opportunity for extensive discussions with many European scientists, who have contributed substantially to my understanding of this problem. In particular, I would like to acknowledge the help of Drs. R. Chesselet and G. Lambert here in Gif, and Dr. C. E. Junge of the Max Planck Institut in Mainz (Federal Republic of Germany).

\section{References}

[1] Kritz, M. A. and Rosner, D. E., submitted to J. Geophys. Res. (1975).

[2] Kritz, M. A., Ph. D. Thesis, Yale University, 1975.

[3] Cronin, J. F., Science 172 (1971) 847.

[4] Friend, J. P., Yearbook of Science and Technology (McGraw Hill, New York) 1972.

[5] Junge, C. E., Chagnon, C. W. and Manson, J. E., J. Meteor. 18 (1961) 81.

[6] Mossop, S. C., Geochim. Cosmochim. Acta 29 (1965) 201.

[7] Friend, J. P., Tellus 28 (1966) 465.

[8] Junge, C. E., J. Meteor. 18 (1961) 501.

[9] ChaGnon, C. W. and Junge, C. E., J. Meteor. 18 (1961) 746.

[10] Junge, C. E., Proc. IAMAP Meeting, Melbourne, Australia 1 (1974) 85.

[11] Hoang, C. T. and Servant, J., C. R. Hebd. Sean. Acad. Sci. 268 (1969) 1049.

[12] Newell, R. E., Kioson, J. W. and Vincent, D. G., Nature 222 (1970) 76.

[13] Newell, R. E., Nature 226 (1970) 70.

[14] Palmen, E. and Newton, C. W., Atmospheric Circulation Systems (Ed. Academic Press, New York) 1969.

[15] NeWell, R. E., Kidson, J. W., VinCent, D. G. and Boer, G. J., The General Circulation of the Tropical Atmosphere, Vol. 2 (The M.I.T. Press, Cambridge (USA) and London (England)) 1974.

[16] Dutsch, H. O., J. Geophys. Res. 75 (1970) 1707.

[17] NCAR, NCAR Quarterly $\mathbf{n}^{\circ} 32,1971,4$.

[18] Newton, C. W., Tellus 18 (1966) 699.
[19] Lodge, J. P., Machado, P. A., Pate, J. B., Sheesley, D. C. and WartburG, A. F., Tellus 26 (1974) 250.

[20] Mason, J. B., The Physics of Clouds (Oxford University Press) 1957.

[21] Slinn, W. G. N. and Hales, J. M., J. Atmos. Sci. 28 (1971) 1465.

[22] Rosinski, J., Rev. Geophys. and Space Physics 12 (1974) 129.

[23] Junge, C. E., Air Chemistry and Radioactivity (Academic Press, New York) 1963.

[24] TwomeY, S., J. Atmos. Sci. 28 (1971) 377.

[25] Mrrabel, P. and Katz, J. L., J. Chem. Phys. 60 (1974) 1138.

[26] Kiang, C. S. and Staufrer, D., Faraday Symp. 7, Fogs and Smokes, Ed. The Chemical Society, London, 1974.

[27] Junge, C. E. and McLaren, E., J. Atmos. Sci. 28 (1971) 382.

[28] Fitzgerald, J. W., J. Atmos. Sci. 30 (1973) 628.

[29] Fox, R. J., Grams, G. W., Schuster, B. G. and Weinman, J. A., J. Geophys. Res. 78 (1973) 7789.

[30] Molina, M. J. and Rowland, F. S., Nature 249 (1974) 810.

[31] Crutzen, P. J., Geophys. Res. Lett. 1 (1974) 205.

[32] Wofsy, S. C., McElroy, M. B. and Sze, N. D., Science 185 (1975) 535.

[33] Chapman, S., Mem. R. Meteorol. Soc. 3 (1930) 103.

[34] BATES, D. R. and Nicolet, M., J. Geophys. Res. 55 (1950) 301.

[35] Crutzen, P. J., Q. J. R. Meteorol. Soc. 96 (1970) 320.

[36] Duce, R. A., J. Geophys. Res. 74 (1969) 4597.

[37] Chesselet, R., Morelli, J. and Buat-Ménard, P., Nobel Symposium 20, The changing Chemistry of the Oceans (Wiley Interscience, New York and London) 1972, 93.

[38] Lovelock, J. E., Nature 256 (1975) 193.

[39] NEwKIRK, G. and Eddy, J. A., J. Atmosph. Sci. 21 (1964) 35 